\title{
The Detection of THCA Using 2-Dimensional Gas Chromatography-Tandem Mass Spectrometry in Human Fingernail Clippings: Method Validation and Comparison with Head Hair
}

\author{
Joseph Jones, Mary Jones, Charles Plate, Douglas Lewis \\ United States Drug Testing Laboratories, Inc., Des Plaines, USA \\ Email: joe.jones@usdtl.com
}

Received July 1, 2013; revised August 1, 2013; accepted August 20, 2013

Copyright (C) 2013 Joseph Jones et al. This is an open access article distributed under the Creative Commons Attribution License, which permits unrestricted use, distribution, and reproduction in any medium, provided the original work is properly cited

\begin{abstract}
Marijuana use as well as abuse is a significant public health and public safety concern in the United States and using hair to identify marijuana users and abusers has been gaining acceptance in a number of venues including workplace, court ordered, and substance abuse treatment monitoring. After the presentation of a fully validated 2-dimensional gas chromatography-tandem mass spectrometry method for the detection of 11-nor-9-carboxy- $\Delta^{9}$-tetrahydrocannabinol (THCA), the chief metabolite of the main psychoactive compound in marijuana, $\Delta^{9}$-tetrahydrocannabinol (THC), we evaluated the usefulness of fingernail clippings as an alternative specimen type to hair by the analysis of a set of 60 matched pairs of head hair and fingernail clippings. The limit of detection was $10 \mathrm{fg} / \mathrm{mg}$, the limit of quantitation was $20 \mathrm{fg} / \mathrm{mg}$, and the assay was linear from $20 \mathrm{fg} / \mathrm{mg}$ to $500 \mathrm{fg} / \mathrm{mg}$. The intra- and inter-assay imprecision and bias studies at 4 different concentrations $(50,100,500$, and $1000 \mathrm{fg} / \mathrm{mg}$ ) were acceptable where all $\%$ Target observations were within $16 \%$ of their expected concentrations and all $\% \mathrm{CV}$ calculations were less than $13.5 \%$. THCA was detectable in more fingernail specimens (53.3\%) than hair specimens (46.7\%) and the mean concentrations in nails were on average 4.9 times higher than in hair $(1813 \mathrm{fg} / \mathrm{mg}$ and $364 \mathrm{fg} / \mathrm{mg}$, respectively). The THCA concentrations in hair and nail were strongly associated $(\mathrm{r}=0.974, P<0.01, \mathrm{n}=60)$ and the association was significant. The study demonstrated that fingernail clippings are a suitable alternative specimen type to hair to monitor for marijuana use and abuse.
\end{abstract}

Keywords: 11-Nor-9-Carboxy- $\Delta^{9}$-Tetrahydrocannabinol; THCA; Carboxy-THC; Hair; Fingernail; 2D-GC-MS/MS; 2-Dimensional Gas Chromatography Tandem Mass Spectrometry

\section{Introduction}

The most commonly used illicit drug in the United States is marijuana; and according to recent reports, the rate of usage has increased while the perception of risk has decreased [1]. Marijuana use has a number of long-term negative health outcomes, such as addiction, respiratory and mental health issues while short-term negative outcomes include impairment of short term memory, judgment, coordination, balance and loss of attention [2]. Marijuana use has been associated with a number of negative employment consequences, such as increased absences, tardiness and accidents, and one recent survey found that $6.8 \%$ of those involved in traffic accidents tested positive for marijuana [2]. The ability to monitor for marijuana use and abuse with objective biomarkers is an important public health, occupational health, and forensic consideration.

One specimen type that has been gaining popularity over the past 30 years in workplace and court ordered drug testing is hair. The primary advantages of hair testing over other specimen types include a longer window of detection (measured in months rather than days), the lack of gender privacy issues at the time of collection, and a higher degree of integrity of specimen validity because each collection is a direct observed collection [3].

The detection of 11-nor-9-carboxy- $\Delta^{9}$-tetrahydrocannabinol (THCA) in hair to indicate marijuana use has been previously reported in the literature and the cutoff suggested in the "Proposed Revisions to Mandatory Guidelines for Federal Workplace Drug Testing Programs" by the Substance Abuse and Mental Health Ser- 
vices Administration (SAMHSA) was $0.05 \mathrm{pg} / \mathrm{mg}$ (50 fg/mg) [4].

Another specimen type that has shown promise and offers a potentially long detection window (up to 6 months) is fingernail [5-14]. Drugs and drug metabolites, such as THCA, are not only incorporated at the point of origin in the germinal matrix but are also incorporated by the nail bed [15]. As for the nail lengthens, it also thickens as material is incorporated from underneath as it travels along the nail bed. Once the nail emerges beyond the hyponychium (the quick), the clippings contain a drug history of the 6 months as it traveled towards the distal edge. The number of reports in the scientific literature concerning the detection of THCA in fingernail is very limited $[6,16]$.

There are 2 objectives for this manuscript. First, we intend to present a fully validated 2D-GC-MS/MS method for the detection of THCA in human head hair and fingernail with sufficient sensitivity to routinely utilize a single-point cutoff calibrator at the proposed SAMSHA cutoff $(50 \mathrm{fg} / \mathrm{mg})$ and an empirically determined LOQ at $20 \mathrm{fg} / \mathrm{mg}$ ( $40 \%$ of the cutoff calibrator). Second, this method will be used to analyze 60 matched pairs of authentic head hair and fingernails for the presence of THCA from a college-aged population to evaluate the observed relative concentrations.

\section{Materials and Methods}

\subsection{Ethics Statement}

The specimens utilized for this study were de-identified remnants of a previously IRB-approved study (Jones et al., 2012).

\subsection{Subjects}

A sufficient amount from 60 matched pairs of head hair and fingernail specimens remained after the completion of a previous study. The minimum amount of hair or fingernail specimen required for analysis was $10 \mathrm{mg}$. The specimens were collected by the Center for Addiction and Behavioral Health Research, a public/private consortium, located at the University of Wisconsin-Milwaukee. After providing informed consent, hair and fingernail specimen collection procedures were initiated. The hair specimen collection procedure consisted of isolating and cutting approximately 200 strands of hair as close as possible to the scalp from the back of the head. The fingernail collection procedure requested that the participants clip the distal edges of all 10 digits as close as possible without injury to the hyponychium (the quick). The de-identified specimens were secured in a foil wrapper and forwarded to United States Drug Testing Laboratories (Des Plaines, IL, USA) for analysis.

\subsection{Chemicals, Reagents and Materials}

THCA and THCA- $d_{9}$ were purchased from Cerilliant Corporation (Round Rock, TX, USA) as $1 \mathrm{mg} / \mathrm{mL}$ ampoules. Compounds for the cocktail of potentially interfering substances (Table 1) were purchased either as 1 $\mathrm{mg} / \mathrm{mL}$ ampules or solids from Cerilliant Corporation (Round Rock, TX, USA) or Cayman Chemicals (Ann

Table 1. List of potentially interfering substances.

\begin{tabular}{|c|c|}
\hline Drug Class & Compounds \\
\hline Amphetamines & $\begin{array}{l}\text { amphetamine, methamphetamine, 3,4-methylenedioxyamphetmine, 3,4-methylenedioxymethamphetamine, ephedrine, } \\
\text { pseudoephedrine, phenylpropanolamine, phentermine, }\end{array}$ \\
\hline Cocaines & cocaine, cocaethylene, benzoylecgonine, norcocaine \\
\hline Cannabinoids & $\mathrm{THC}$ \\
\hline Opiates & $\begin{array}{l}\text { codeine, dihydrocodeine, morphine, hydrocodone, hydromorphone, oxycodone, oxymorphone, monoacetylmorphine, } \\
\text { buprenorphine, norbuprenophine, nalbuphine, naltrexone, } 6 \beta \text {-naltrexol, butorphanol, meperidine, normeperidine, pentazocine, } \\
\text { tramadol, methadone, 2-ethylidene-1,5-dimethyl-3,3-diphenylpyrrolidine, fentanyl, norfentanyl, sufentanil, alfentanil, } \\
\text { propoxyphene, norpropoxyphene, }\end{array}$ \\
\hline Benzodiazepines & alprazolam, $\alpha$-hydroxyalprazolam, diazepam, nordiazepam, oxazepam, midazolam, triazolam, temazepam \\
\hline Barbiturates & amobarbital, butalbital, pentobarbital, secobarbital, phenobarbital \\
\hline Antidepressants & fluoxetine, norfluoxetine, amitriptyline, nortriptyline, doxepin, nordoxepin, sertraline \\
\hline Antihistamines & pheniramine, chlorpheniramine, brompheniramine, doxylamine, diphenhydramine \\
\hline NSAID $^{\mathrm{a}}$ & ibuprofen, naproxen, ketoprofen, salicylic acid, \\
\hline Miscellaneous & $\begin{array}{l}\text { Lidocaine, cotinine, hydroxycotinine, caffeine, carisoprodol, meprobamate, methylphenidate, ritalinic acid, zolpidem, zopiclone, } \\
\text { actaminophene }\end{array}$ \\
\hline
\end{tabular}

${ }^{\mathrm{a}}$ Non-steroidal Anti-inflammatory drug. 
Arbor, MI, USA). Solid phase extraction cartridges (ZSTHC020) with A $200 \mathrm{mg}$ mixed mode bed and 10 $\mathrm{mL}$ reservoir were purchased from United Chemical Technologies (Bristol, PA, USA). All reagents were ACS grade, all solvents were HPLC grade, and were purchased from Thermo-Fisher Scientific (Hanover Park, IL, USA). Pentafluoropropionic anhydride (DR104, $25 \mathrm{~g}$ ) and hexafluoroisopropanol (DR136, $25 \mathrm{~g}$ ) were purchased from Campbell Science (Rockford, IL, USA).

\subsection{Calibrator, Control, and Internal Standard Spiking Solutions}

A $50 \mathrm{pg} / \mathrm{mL}$ calibrator spiking solution and a $50 \mathrm{pg} / \mathrm{mL}$ control spiking solution were prepared by the appropriate dilution of different lots of $1 \mathrm{mg} / \mathrm{mL}$ THCA reference standard with methanol. A $50 \mathrm{pg} / \mathrm{mL}$ internal standard spiking solution was prepared by the appropriate dilution of the $1 \mathrm{mg} / \mathrm{mL}$ THCA-d9 reference standard with methanol.

\subsection{Preparation of Calibrator and Controls}

A $50 \mathrm{fg} / \mathrm{mg}$ calibrator (single point) was prepared by the addition of $50 \mu \mathrm{L}$ of THCA calibrator spiking solution to $50 \mathrm{mg}$ of certified negative hair or fingernail in a silanized $13 \times 100 \mathrm{~mm}$ screw topped glass tube. The negative, low (20 fg/mg), mid (62.5 fg/mg), and high (400 fg/mg) controls were prepared by the addition of $0,20,62.5$, and $400 \mu \mathrm{L}$ of control spiking standard to $50 \mathrm{mg}$ of certified negative hair or fingernail in silanized $13 \times 100 \mathrm{~mm}$ screw topped glass tubes.

\subsection{Specimen Preparation}

Specimens were prepared by accurately transferring 10 $50 \mathrm{mg}$ of cut hair or fingernail clippings to a silanized 13 $\times 100 \mathrm{~mm}$ screw topped glass tube. The specimens were washed with the addition of $1 \mathrm{~mL}$ of methylene chloride with vortex mixing. The methylene chloride was decanted and the tubes were allowed to dry in the fume hood. Following the addition of $50 \mu \mathrm{L}$ of internal standard solution, the specimens were digested with $1 \mathrm{~mL}$ of $1 \mathrm{~N}$ sodium hydroxide at $80^{\circ} \mathrm{C}$ for 1 hour. After centrifuging at $580 \times \mathrm{g}$ for 20 minutes the supernatant was decanted into silanized $16 \times 125 \mathrm{~mm}$ screw topped glass tubes that already contained $1 \mathrm{~mL}$ glacial acetic acid, 3 $\mathrm{mL} 1 \mathrm{M}$ acetic acid, and $2 \mathrm{~mL} 0.1 \mathrm{M}$ sodium acetate buffer ( $\mathrm{pH}$ 4.5). The mixture was loaded into solid phase extraction columns that were previously conditioned with $3 \mathrm{~mL}$ methanol, $3 \mathrm{~mL}$ DI water, and $1 \mathrm{~mL} 1 \mathrm{~N} \mathrm{HCl}$. After rinsing with $2 \mathrm{~mL}$ DI water, $2 \mathrm{~mL} 0.1 \mathrm{M} \mathrm{HCl} /$ Acetonitrile (70/30), and $0.1 \mathrm{~mL}$ isooctane, the columns were eluted with $3.0 \mathrm{~mL}$ of hexane/ethyl acetate $(75 / 25)$ and evaporated under a stream of nitrogen at $40^{\circ} \mathrm{C}$. The
HFIP-PFPA derivative of THCA was prepared with the addition of $50 \mu \mathrm{L}$ of HFIP and $100 \mu \mathrm{L}$ of PFPA and incubated in a dry bath for 20 minutes at $70^{\circ} \mathrm{C}$.

\subsection{2-D GC-MS/MS Conditions}

The specimens were analyzed using an Agilent Technologies (Santa Clara, CA, USA) 7890A GC equipped with a LTM Series II System, Agilent Dean's Switch and 7693 Autosampler. Samples were injected in the splitless mode. Separation was achieved using two-dimensional gas chromatography with helium as the carrier gas. The initial column was an Agilent J\&W DB-1MS $15 \mathrm{~m} \times$ $0.25 \mathrm{~mm} \times 0.25 \mu \mathrm{m}$, (Santa Clara, CA, USA), the temperature was held at $100^{\circ} \mathrm{C}$ for 2 minutes then ramped to $210^{\circ} \mathrm{C}$ at $200^{\circ} \mathrm{C} /$ minute followed by a ramp to $300^{\circ} \mathrm{C}$ at $10^{\circ} \mathrm{C}$ per minute in 9.2 minutes. The flow from the first column was diverted to the second column for $0.3 \mathrm{~min}$ utes with the Dean's Switch pressure valve at $7.15 \mathrm{~min}$ utes. The second column was an Agilent J\&W DB-17MS $15 \mathrm{~m} \times 0.25 \mathrm{~mm} \times 0.25 \mu \mathrm{m}$ (Santa Clara, CA, USA), the temperature was held at $100^{\circ} \mathrm{C}$ until 7.6 minutes then ramped to $230^{\circ} \mathrm{C}$ at $200^{\circ} \mathrm{C}$ per minute by 8.25 minutes followed by a ramp to $280^{\circ} \mathrm{C}$ at $10^{\circ} \mathrm{C}$ per minute in 9.2 minutes. The transfer line temperature was maintained at $280^{\circ} \mathrm{C}$

The detector was an Agilent 7000 tandem mass spectrometer (Santa Clara, CA, USA) operated in the negative chemical ionization mode using ammonia as the reagent gas and Argon as the collision gas. The internal standard (THCA- $d_{9}$ ) was monitored using the $\mathrm{m} / z 629.0$ $>501.0$ (quantification ion; $\mathrm{CE}=5$ ) and $\mathrm{m} / z 629.0>$ 392.0 (qualifying ion; $\mathrm{CE}=5$ ) transitions where $\mathrm{CE}$ is the Collision Energy (V). The $m / z 620.0>492.0$ (quantification ion; $\mathrm{CE}=5$ ) and $\mathrm{m} / z 620.0>383.0$ (qualifying ion; $\mathrm{CE}=5$ ) transitions were used to monitor THCA. All data were processed using Agilent Technologies Mass Hunter software version B.05.00 (Santa Clara, CA, USA).

\subsection{Identification Criteria}

The identification criteria used for this procedure included four components: retention time, signal to noise, baseline resolution, and relative ion intensity. The retention time of each analyte was required to be within 0.2 min of the retention time established by the single point calibrator. A signal to noise ratio of greater than 3:1 was required of each ion chromatogram. A minimum of $90 \%$ return to baseline was required to consider a peak to be adequately resolved from a co-eluting peak. The relative ion intensity of the product ions for each analyte (mass ratio) was required to be within $20 \%$ of the corresponding relative ion intensity that was established by the single point calibrator. 


\subsection{Validation}

This method is a slightly modified version of a method that first appeared as an application note in the trade journal American Laboratory [17]. The method validation procedure was developed using recommendations of commonly accepted guidelines $[18,19]$. The following parameters were evaluated for both hair and fingernail: limit of detection (LOD), limit of quantitation (LOQ), linear range, carryover potential, selectivity, bias, imprecision, extraction efficiency, stability of extracts on the autosampler, and stability of specimens during freezethaw conditions.

The LOD and LOQ were determined by analyzing a series of fortified controls in triplicate. The LOQ was the lowest point where the mean of the measured concentrations was within $20 \%$ of target value and satisfied all identification criteria. The LOD was the lowest triplicate that satisfied all identification criteria without consideration of the measured concentration. The concentrations assayed were 10, 20, 40 and $50 \mathrm{fg} / \mathrm{mg}$.

Linearity was determined by analyzing a series of fortified negative controls in replicates of five. Calibration curves were constructed using analyte/internal standard area response ratios. A weighted $(1 / \times)$ least squares linear regression was used to mitigate heteroscedasticity. The concentrations tested were $20,40,50,100,250$, and $500 \mathrm{fg} / \mathrm{mg}$. Each point was required to be within $15 \%$ of target with the exception of the LOQ (20 fg/mg) where $20 \%$ was allowed.

The potential for carryover was determined by analyzing a known negative control after a control containing $5000 \mathrm{fg} / \mathrm{mg}$. A successful carryover challenge must be less than the determined LOD $(10 \mathrm{fg} / \mathrm{mg})$.

Evaluating 6 negative controls spiked with a cocktail of potentially interfering substances $(2000 \mathrm{pg} / \mathrm{mg})$ assessed the specificity of the assay. The results of the 6 controls must be less than the LOD (10 fg/mg) of the assay (Table 1). Analyzing $6 \mathrm{LOQ}$ controls $(20 \mathrm{fg} / \mathrm{mg}$ ) fortified with the cocktail of potentially interfering compounds challenged the selectivity of the method. All 6 replicates must satisfy the identification criteria and the measured concentrations must be within $20 \%$ of target value.

Bias and imprecision were determined by analyzing prepared controls at four different concentrations, replicates of five over four different days. The concentrations investigated were $50,100,500$, and $1000 \mathrm{fg} / \mathrm{mg}$. The bias and imprecision challenge was considered to be successful if each intra-assay mean and inter-assay mean were within $15 \%$ of target value and the maximum intra- and inter-assay variance were less than $20 \%$, respectively.

The extraction efficiency was determined by compareing the mean area responses of 2 sets of extracted controls (target concentration $=50 \mathrm{fg} / \mathrm{mg}, \mathrm{n}=5$ ) where set 1 was spiked prior to extraction and set 2 was spiked after elution from the SPE cartridge. The efficiency of the recovery of THCA from the residue of authentic hair and fingernail was evaluated by performing 3 successive extractions on the remaining residue of an authentic hair and nail specimen.

The stability of prepared extracts was assessed by the reanalysis of a control set $(50,100,500$, and $1000 \mathrm{fg} / \mathrm{mg})$ that had been stored at room temperature for five days. The stability was expressed as a ratio of the results of the incubated controls and the original measured concentrations. The stability of the specimens to freeze-thaw conditions was evaluated by subjecting five control sets (50, 100,500 , and $1000 \mathrm{fg} / \mathrm{mg}$ ) to three daily freeze-thaw cycles. Freeze-thaw stability was expressed as a ratio of the observed means versus the respective target concentration.

\subsection{Statistical Analysis}

Statistical analysis was performed using IBM $^{\circledR}$ SPSS $^{\circledR}$ Statistics version 19.0.0. Pearson correlations were used to evaluate the association between hair THCA and nail THCA concentrations. A paired-sample $t$-test $(\mathrm{t})$ was used to compare the means of THCA concentrations in hair and fingernails. A probability of $P \leq 0.05$ was considered to be significant.

\section{Results}

The parameters for the chromatography and mass spectrometry were consistent with previous reports [16, 20-27]. The transitions described previously proved to be clean and stable throughout the validation process. The number of identification points for THCA was 4, satisfying the commonly accepted recommendation of at least 3 identification points [19]. Extracted ion chromatograms of a $20 \mathrm{fg} / \mathrm{mg}$ LOQ control of THCA are presented in Figure 1.

The determined LOD for this method was $10 \mathrm{fg} / \mathrm{mg}$. The method allowed for the proper identification of THCA for the 50, 20 and $10 \mathrm{fg} / \mathrm{mg}$ controls. The mean of the measured concentrations at $10 \mathrm{fg} / \mathrm{mg}$ was outside the acceptable limit of $20 \%$, therefore the LOQ for this assay was $20 \mathrm{fg} / \mathrm{mg}$. All identification criteria and quantitation criteria for the $20 \mathrm{fg} / \mathrm{mg}$ controls were acceptable with a mean concentration of $20.2 \mathrm{fg} / \mathrm{mg}$ and $19.9 \mathrm{fg} / \mathrm{mg}$ and \% $\mathrm{CV}$ of 8.1 and 8.7 for hair and fingernail, respectively.

Linearity of the method was assessed by replicate analysis $(\mathrm{n}=5)$ of negative hair and fingernail fortified with $20,40,50,100,250$, and $500 \mathrm{fg} / \mathrm{mg}$ of THCA.

Standard lines were constructed using a $1 / \times$ weighted linear regression. The assessment for hair yielded a mean slope of $2.61 \times 10^{-2} \pm 1.40 \times 10^{-3}$, an intercept of 2.03 $\times 10^{-1} \pm 1.21 \times 10^{-1}$ and a mean coefficient of determina- 

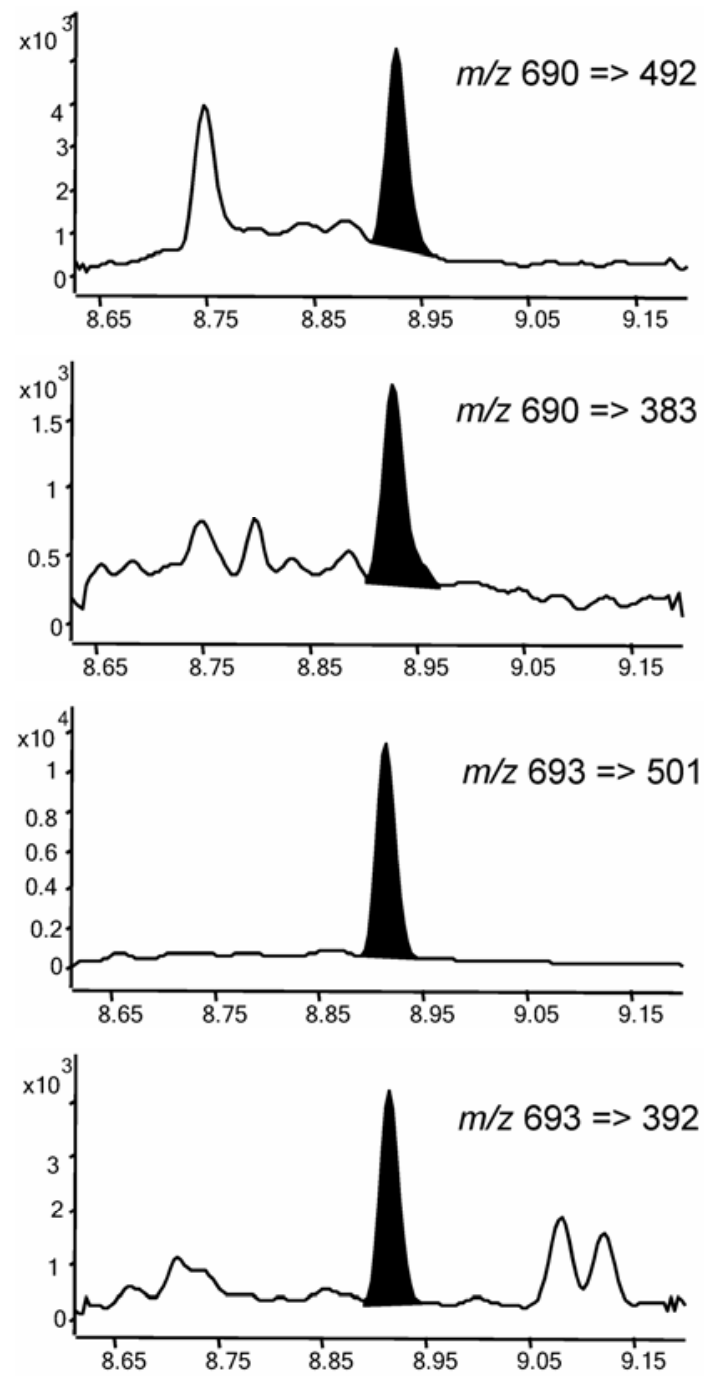

Figure 1. Multiple reaction monitoring chromatograms for THCA and $d_{9}$-THCA for a control fortified at the LOQ (20 fg/mg).

tion $\left(\mathrm{r}^{2}\right)$ of $0.9897 \pm 4.47 \times 10^{-3}$. The assessment for fingernail yielded a mean slope of $2.48 \times 10^{-2} \pm 1.10 \times 10^{-3}$, an intercept of $1.41 \times 10^{-1} \pm 1.19 \times 10^{-1}$ and a mean coefficient of determination $\left(\mathrm{r}^{2}\right)$ of $0.9791 \pm 8.90 \times 10^{-3}$. All points were within $15 \%$ of target value.

THCA was not detected at or above the LOD (10 $\mathrm{fg} / \mathrm{mg}$ ) in a negative hair or fingernail control analyzed immediately following a hair or fingernail control fortified with $5000 \mathrm{fg} / \mathrm{mg}$ of THCA. The potential for carryover at $5000 \mathrm{fg} / \mathrm{mg}$ of THCA was acceptable. Based on these findings, any specimen that followed a specimen with an on-column value greater than $5000 \mathrm{fg} / \mathrm{mg}$ was reanalyzed following a clean solvent injection.

Negative controls spiked with the cocktail of interfereing compounds (Table 1) did not exhibit any detectable THCA at or above the reported LOD (10 fg/mg). The selectivity of the method was acceptable as evidenced by successful analysis of 6 LOQ controls prepared from negative control material that were spiked (2000 pg/mg) with a cocktail of potentially interfering compounds. The mean of the hair LOQ controls was $22.1 \mathrm{fg} / \mathrm{mg}$ with a $\% \mathrm{CV}$ of $14.7 \%$ and the mean of the fingernail LOQ controls was $21.72 \mathrm{fg} / \mathrm{mg}$ with a $\% \mathrm{CV}$ of $14.6 \%$.

The intra- and inter-assay bias challenges for both hair and fingernail were within $13.8 \%$ of expected concentration. The intra- and inter-assay imprecision experiments for both hair and fingernail were less than $13.6 \%$. The bias and imprecision of the method was acceptable according to the chosen guidelines. The bias and imprecision experiment results are posted in Table 2.

The determined extraction efficiency (ratio of mean area responses of pre-extraction spiked and post-extraction spiked controls) was $53.6 \%$ for controls spiked with $50 \mathrm{fg} / \mathrm{mg}$ THCA. The recovery of THCA was $92.4 \%$ and $91.8 \%$ on the first extraction $7.0 \%$ and $7.3 \%$ on the second extraction and $0.6 \%$ and $0.9 \%$ on the third extraction from authentic hair and fingernail, respectively.

Re-injection of hair and fingernail control sets (50, 100, 500 , and $1000 \mathrm{fg} / \mathrm{mg}$ ) after incubating 4 days at room temperature did not demonstrate any obvious degradation. The results ranged from $96.6 \%$ to $107.7 \%$ of the original measured concentrations. The 5 control sets subjected to 3 freeze-thaw cycles proved to be stable. The \% Target values ranged from $93.2 \%$ to $114.8 \%$.

\section{Authentic Specimens}

Of the 60 matched pairs, 28 (46.7\%) hair specimens and $32(53.3 \%)$ fingernail specimens were positive according to the proposed SAMHSA cutoff $(50 \mathrm{fg} / \mathrm{mg}$ ). Hair concentrations ranged from $<$ LOD to $9011 \mathrm{fg} / \mathrm{mg}$ (mean $=$ $364.29 \pm 1216.74 \mathrm{fg} / \mathrm{mg}$; median $=45.72 \mathrm{fg} / \mathrm{mg}$ ) and fingernail concentrations ranged from $<$ LOD to 51,569 $\mathrm{fg} / \mathrm{mg}$ (mean $=1813.49 \pm 6952.42 \mathrm{fg} / \mathrm{mg}$; median $=$ $58.33 \mathrm{fg} / \mathrm{mg}$ ). A comparison of means using a pairedsample $t$-test demonstrated a mean difference of $1449.2 \pm$ $745.3 \mathrm{fg} / \mathrm{mg}(\mathrm{t}=1.944, \mathrm{df}=59, P<0.05)$ and the difference was significant. The Pearson product-moment correlation coefficient $(\mathrm{r})$ of the matched pairs was $0.974(P$ $<0.01, \mathrm{n}=60)$, a strong positive correlation that was significant. The comparison of THCA found in head hair and fingernail are shown in Figure 2.

\section{Discussion}

This study presented a fully validated procedure for the analysis of THCA in human head hair and fingernail clippings and this method was used to compare the observed concentrations of matched pairs of head hair and fingernails from a population of college-aged donors. We evaluated the hypothesis that fingernail can be used to routinely monitor for marijuana use. The data presented 
Table 2. The bias and imprecision of THCA in hair and fingernails.

\begin{tabular}{|c|c|c|c|c|c|}
\hline \multirow{2}{*}{ Specimen Type } & \multirow[b]{2}{*}{ Target (fg/mg) } & \multicolumn{2}{|c|}{ Intra-assay $(\mathrm{n}=5)$} & \multicolumn{2}{|c|}{ Inter-assay $(\mathrm{n}=20)$} \\
\hline & & Accuracy (\%) & Precision $(\% \mathrm{CV})$ & Accuracy $(\%)$ & Precision $(\% \mathrm{CV})$ \\
\hline \multirow[t]{4}{*}{ Hair } & 50 & $94.8-106.5$ & $3.0-9.4$ & 101.6 & 7.7 \\
\hline & 100 & $101.2-113.1$ & $6.9-9.6$ & 107.1 & 8.8 \\
\hline & 500 & $86.4-101.7$ & $6.6-10.2$ & 93.8 & 9.5 \\
\hline & 1000 & $96.1-110.8$ & $3.8-7.4$ & 101.5 & 8.5 \\
\hline \multirow[t]{4}{*}{ Fingernail } & 50 & $94.9-99.6$ & $3.8-9.2$ & 96.3 & 7.1 \\
\hline & 100 & $88.5-102.0$ & $3.6-7.9$ & 95.8 & 8.0 \\
\hline & 500 & $102.6-116.0$ & $2.3-6.0$ & 110.5 & 5.2 \\
\hline & 1000 & $113.0-113.8$ & $3.3-13.5$ & 113.2 & 7.6 \\
\hline
\end{tabular}

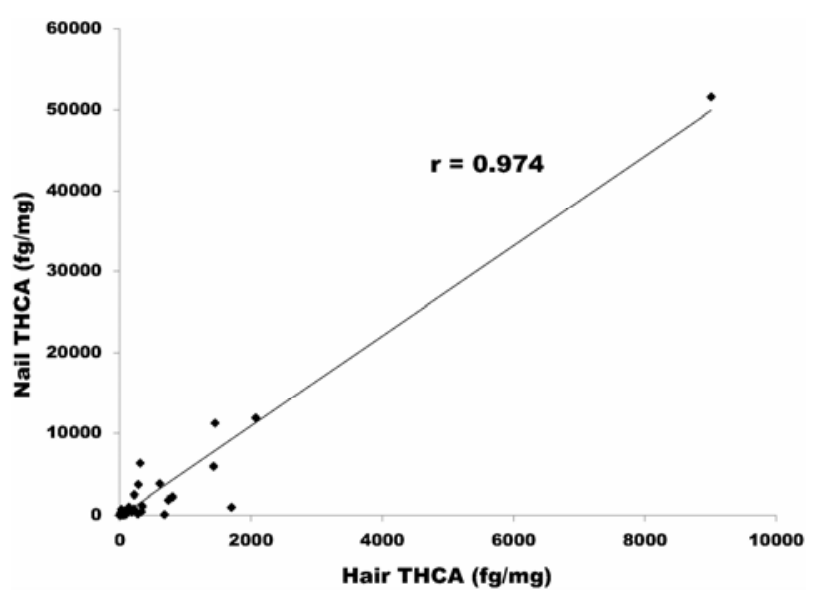

Figure 2. Comparison of observed concentration of THCA between matched pairs of head hair and fingernails in a college-aged population.

here revealed that fingernail is not only a suitable alternative specimen type for monitoring marijuana use but suggests that it may be a preferred specimen type for the detection of THCA.

The mean observed concentration of THCA in head hair was $364.3 \mathrm{fg} / \mathrm{mg}$ and the amount of THCA in fingernail was almost 5 times higher with a mean concentration of $1813.5 \mathrm{fg} / \mathrm{mg}$. The Student's $t$-test revealed that the observed difference of these means was significant $(\mathrm{t}$ $=1.944, P<0.05)$. This increase in the observed concentration of THCA in fingernail was at least partially responsible for the higher positivity rate at the proposed SAMSHA cutoff $(50 \mathrm{fg} / \mathrm{mg})$, where $46.7 \%$ of the hair were positive and $53.3 \%$ of the fingernails were positive. Additionally, a strong association was demonstrated between the observed concentration of THCA in head hair and fingernail $(\mathrm{r}=0.974 ; P<0.01)$.

The hair concentrations reported in this study were similar to and consistent with other recently published studies. Moore, Guzaldo, and Donahue [20] reported
THCA in the hair of self-reported cannabis users ranging from $600 \mathrm{fg} / \mathrm{mg}$ to $12,900 \mathrm{fg} / \mathrm{mg}$ using a bench top single quadrupole GC/MS in the negative chemical ionization mode equipped with a high volume injection apparatus $(\mathrm{LOQ}=400 \mathrm{fg} / \mathrm{mg})$. In a later study, Moore et al. [21], using a more sensitive two-dimensional GC strategy $(\mathrm{LOQ}=50 \mathrm{fg} / \mathrm{mg})$, reported THCA concentrations ranging from $90 \mathrm{fg} / \mathrm{mg}$ to $1980 \mathrm{fg} / \mathrm{mg}$ in the hair of 13 selfreported marijuana users. Other studies with LOQ's of 50 or $100 \mathrm{fg} / \mathrm{mg}$ reported hair concentrations of $50 \mathrm{fg} / \mathrm{mg}$ to $11,680 \mathrm{fg} / \mathrm{mg}$ using GC-MS/MS platforms [22-27]. In our study, the concentrations of THCA in hair ranged from $10 \mathrm{fg} / \mathrm{mg}$ to $9011 \mathrm{fg} / \mathrm{mg}$ (mean $=364.29 \pm 1216.74$ $\mathrm{fg} / \mathrm{mg}$ ).

Our findings for THCA in nails are much lower than previous reports. The first report of THCA in nail reported $9.82 \mathrm{ng} / \mathrm{mg}$ and $29.67 \mathrm{ng} / \mathrm{mg}$ in two nail specimens from known cannabis users [6]. A second study using a GC-MS/MS platform reported 1 positive out of 9 at a level of $200 \mathrm{pg} / \mathrm{mg}$ [16]. Our study found levels ranging from $10 \mathrm{fg} / \mathrm{mg}$ to $51,569 \mathrm{fg} / \mathrm{mg}$ (mean $=1813.49$ $\pm 6952.42 \mathrm{fg} / \mathrm{mg}$ ), which are much less than these previous two reports.

There were several limitations of this study that should be addressed. First, one limitation of this study was the absence of accurate self-report of marijuana use or verified dose administration of marijuana to compare the observed concentrations found in the hair and fingernail. A second limitation of this study was the absence of demographic information for the participants to control for gender, race, or age differences. Third, the positivity rates are not generalizable to the population tested or the general population because they were not randomly selected but were a simple convenience sampling of remaining remnants from a previous study. Lastly, detailed information concerning personal hygiene and cosmetic treatment was not available. Future investigations are needed to evaluate the effects of these limitations. 


\section{Conclusion}

We concluded that fingernail is a suitable alternative to hair for the detection of THCA. Additionally, our data suggested that fingernail clippings may be the preferred specimen type. The observed concentrations of THCA in fingernail clippings were over 4 times greater than the observed concentrations in matched head hair specimens making detection more likely. The use of fingernail as a specimen type for THCA analysis provides the substance abuse professional with one additional tool to detect marijuana use in a number of settings such as workplace, court-ordered, prenatal care and substance abuse treatment monitoring.

\section{Acknowledgements}

The authors of this manuscript are employees of United States Drug Testing Laboratories, a privately owned commercial reference laboratory. This study was funded by United States Drug Testing Laboratories. The funding source had no role in study design, data collection and analysis, decision to publish, or preparation of the manuscript. The authors would like to thank Mr. Brian Jones for his efforts assisting with the analysis of the specimens used in this report.

\section{REFERENCES}

[1] National Institute of Drug Abuse (NIDA), "DrugFacts: Marijuana," 2012.

http://www.drugabuse.gov/publications/drugfacts/marijua na

[2] National Institute of Drug Abuse (NIDA), "Research Report Series: Marijuana Abuse," 2012a. http://www.drugabuse.gov/sites/default/files/rrmarijuana. pdf

[3] W. Baumgartner, V. Hill and W. Blahd, "Hair Analysis for Drugs of Abuse," Journal of Forensic Science, Vol. 34, No. 6, 1989, pp. 1433-1453.

[4] Substance Abuse and Mental Health Services Administration (SAMHSA), "Proposed Revisions to Mandatory Guidelines for Federal Workplace Drug Testing Programs," Federal Register, Vol. 69, No. 71, 2004, pp. 19673-19732.

[5] G. Skopp and L. Pötsch, "Drug Screening of Nail Clippings to Detect Prenatal Drug Exposure," Therapeutic Drug Monitoring, Vol. 19, No. 4, 1997, pp. 386-389. http://dx.doi.org/10.1097/00007691-199708000-00004

[6] N. Lemos, R. Anderson and J. Roberson, "Nail Analysis for Drugs of Abuse: Extraction and Determination of Cannabis in Fingernails by RIA and GC-MS," Journal of Analytical Toxicology, Vol. 23, 1999, pp. 147-152. http://dx.doi.org/10.1093/jat/23.3.147

[7] J. Ropero-Miller, B. Goldberger, E. Cone and R. Joseph, "The Disposition of Cocaine and Opiate Analytes in Hair and Fingernails of Humans Following Cocaine and Co- deine Administration," Journal of Analytical Toxicology, Vol. 24, 2000, pp. 496-508.

http://dx.doi.org/10.1093/jat/24.7.496

[8] M. Cingolani, S. Scavella, R. Mencarelli, D. Mirtella, R. Froldi and D. Rodriguez, "Simultaneous Detection and Quantitation of Morphine, 6-Acetylmorphine, and Cocaine in Toenails: Comparison with Hair Analysis," Journal of Analytical Toxicology, Vol. 28, No. 2, 2004, pp. 128-131. http://dx.doi.org/10.1093/jat/28.2.128

[9] J. Jenkins and D. A. Engelhart, "Phencyclidine Detection in Nails," Journal of Analytical Toxicology, Vol. 30, 2006, pp. 643-644. http://dx.doi.org/10.1093/jat/30.8.643

[10] S. Valentecampos, M. Yonamine, R. Moreau and O. Silva, "Validation of a Method to Detect Cocaine and its Metabolites in Nails by Gas chromatography-Mass Spectrometry," Forensic Science International, Vol. 159, No. 2-3, 2006, pp. 218-222.

[11] R. Irving and S. Dickson, "The Detection of Sedatives in Hair and Nail Samples using Tandem LC-MS-MS," Forensic Science International, Vol. 166, No. 1, 2007, pp. 58-67. http://dx.doi.org/10.1016/j.forsciint.2006.03.027

[12] L. Morini, M. Colucci, M. Ruberto and A. Groppi, "Determination of Ethyl Glucuronide in Nails by Liquid Chromatography Tandem Mass Spectrometry as a Potential New Biomarker for Chronic Alcohol Abuse and Binge Drinking," Analytical and Bioanalytical Chemistry, Vol. 402, No. 5, 2012, pp. 1865-1870. http://dx.doi.org/10.1007/s00216-011-5609-8

[13] J. Jones, M. Jones, C. Plate, D. Lewis, M. Fendrich, L. Berger and D. Fuhrmann, "Liquid ChromatographyTandem Mass Spectrometry Assay to Detect Ethyl Glucuronide in Human Fingernail: Comparison to Hair and Gender Differences," American Journal of Analytical Chemistry, Vol. 3, No. 1, 2002, pp. 83-91.

[14] Keten, C. Zeren, M. Arslan, N. Daglioglu, R. Karanfil and B. Sen, "Determination of Ethyl Glucuronide in Fingernails by LC/MS-MS," Romanian Journal of Legal Medicine, Vol. 21, No. 1, 2013, pp. 67-72.

[15] Palmeri, S. Pichini, R. Pacifici, P. Zuccaro and A. Lopez, "Drugs in Nails: Physiology, Pharmacokinetics and Forensic Toxicology," Clinical Pharmacokinetics, Vol. 38, No. 2, 2000, pp. 95-110. http://dx.doi.org/10.2165/00003088-200038020-00001

[16] J. Kim, J. Cheong, M. Kim, J. Lee and M. In, "Simultaneous Determination of Amphetamine-Type Stimulants and Cannabinoids in Fingernails by Gas Chromatography-Mass Spectrometry," Archives of Pharmacal Research, Vol. 31, No. 6, 2008, pp. 805-813. http://dx.doi.org/10.1007/s12272-001-1230-5

[17] D. Engelhart, F. Feyerherm, S. Baumann and B. Rothweiler, "Rapid, Robust, and Sensitive Detection of 11-nor- $\Delta 9$-Tetrahydrocannabinol-9-Carboxylic Acid in Hair," American Laboratory, Vol. 43, No. 9, 2011 p. 18.

[18] Food and Drug Administration, Center for Drug Evaluation Research, Center for Veterinary Medicine, "Guidance for Industry: Bioanalytical Method Validation," 2001. http://www.fda.gov/downloads/Drugs/GuidanceComplian ceRegulatoryInformation/Guidances/ucm070107.pdf

[19] The Commission of the European Communities, "Official 
Journal of the European Communities L," Vol. 221, 2002, p. 8.

[20] C. Moore, F. Guzaldo and T. Donahue, "The Determination of 11-nor- $\Delta^{9}$-Tetrahydrocannabinol-9-Carboxylic Acid (THC-COOH) in Hair using Negative Ion Gas Chromatography-Mass Spectrometry and High-Volume Injection," Journal of Analytical Toxicology, Vol. 25, No. 7, 2001, pp. 555-558. http://dx.doi.org/10.1093/jat/25.7.555

[21] C. Moore, S. Rana, C. Coulter, F. Feyerherm and H. Prest, "Application of Two-Dimensional Gas Chromatography with Electron Capture Chemical Ionization Mass Spectrometry to the Detection of 11-nor- $\Delta^{9}$-Tetrahydro cannabinol-9-Carboxylic Acid (THC-COOH) in Hair," Journal of Analytical Toxicology, Vol. 30, No. 3, 2006, pp. 171-177. http://dx.doi.org/10.1093/jat/30.3.171

[22] M. Huestis, R. Gustafson, E. Moolchan, A. Barnes, J. Bourland, S. Sweeney, E. Hayes, P. Carpenter and M. Smith, "Cannabinoid Concentrations in Hair from Documented Cannabis Users," Forensic Science International, Vol. 169, No. 2, 2007, pp. 129-136.

http://dx.doi.org/10.1016/j.forsciint.2006.08.005

[23] E. Han, H. Choi, S. Lee, H. Chung and J. Song, "A Study on the Concentrations of 11-nor- $\Delta^{9}$-Tetrahydro cannabinol-9-Carboxylic Acid (THC-COOH) in Hair Root and Whole Hair," Forensic Science International, Vol. 210, No. 1, 2011, pp. 201-205.

http://dx.doi.org/10.1016/j.forsciint.2011.03.017
[24] E. Han, H. Choi, S. Lee, H. Chung and J. Song, "A Comparative Study on the Concentrations of 11-nor- $\Delta$ " Tetrahydrocannabinol-9-Carboxylic Acid (THC-COOH) in Head and Pubic Hair," Forensic Science International, Vol. 212, No. 1-3, 2011, pp. 238-241.

[25] J. Kim, J. Cheong, J. Lee and M. In, "Improved Gas Chromatography-Negative Ion Chemical Ionization Tandem Mass Spectrometric Method for Determination of 11-nor- $\Delta^{9}$-Tetrahydrocannabinol-9-Carboxylic Acid in Hair using Mechanical Pulverization and Bead-Assisted Liquid-Liquid Extraction," Forensic Science International, Vol. 206, No. 1-3, 2011, pp. e99-e102.

[26] E. Han, Y. Park, E. Kim, S. In, W. Yang, S. Lee, H. Choi, S. Lee, H. Chung and J. Song, "Simultaneous analysis of $\Delta^{9}$-Tetrahydrocannabinol and 11-nor-9-Carboxy-Tetrahydrocannabinol in Hair without Different Sample Preparation and Derivatization by Gas Chromatogra-phyTandem Mass Spectrometry," Journal of Pharmaceutical and Biomedical Analysis, Vol. 55, No. 5, 2011, pp. 10961103. http://dx.doi.org/10.1016/i.jpba.2011.03.020

[27] E. Han, H. Chung and J. Song, "Segmental Hair Analysis for 11-nor- $\Delta^{9}$-Tetrahydrocannabinol-9-Carboxylic Acid and the Patterns of Cannabis Use," Journal of Analytical Toxicology, Vol. 36, No. 3, 2012, pp. 195-200. http://dx.doi.org/10.1093/jat/bks010 